EESTI NSV TEADUSTE AKADEEMIA TOIMETISED. $\mathrm{X}$ KOIDE FOOSIKALIS-MATEMAATILISTE JA TEHNILISTE TEADUSTE SEERIA. 1961, NR. 1

ИЗВЕСТИЯ АКАДЕМИИ НАУК ЭСТОНСКОИ ССР. ТОМ Х СЕРИЯ ФИЗИКО-МАТЕМАТИЧЕСКИХ И ТЕХНИЧЕСКИХ НАУК. 1961, a 1

\title{
ПОЛУЧЕНИЕ МОЮЩИХ ВЕЩЕСТВ ТИПА АЛКИЛАРИЛСУЛЬФОНАТОВ ИЗ ПАРАФИНОВЫХ УГЛЕВОДОРОДОВ СЛАНЦЕВОЙ СМОЛЫ
}

\author{
Г. Г. СТЕПАНОВА, \\ кандидат технических наук
}

\begin{abstract}
Разработанный в Институте химии АН ЭССР метод получения моющих веществ (сульфонола) на базе легких фракций сланцевой смолы предполагает использование олефиновых углеводородов, как содержащихся в исходных фракциях, так и образующихся при хлорцинковой обработке бензиновых фракций [1]. Поскольку олефнновые углеводороды в сланцевой смоле всегда находятся в смеси с парафиновыми, интересно было исследовать поведение последних в процессе синтеза сланцевого сульфонола, а также изучить вопрос о возможности использования парафиновых углеводородов для синтеза моющих веществ.

Получение моющих средств из парафиновых углеводородов сланцевой смолы применялось в $30-\mathrm{x}$ годах в США для сннтеза накконола и сантомирза на базе керосиновых фракций пенсильванских и мичиганских нефтей, а в Германии для синтеза игепала из когазина $\left[{ }^{2,3}\right]$.

Из советских нефтей наиболее пригодными для синтеза моющих веществ подобного типа оказались прямогонные фракции с температурой кипения $180-310^{\circ}$ из грозненской и туймазинской нефтей [4].

Описаны также способы получения алкилбензолсульфонатов из парафиновых углеводородов синтина, предварительно прогидрированного до бромного числа 0,3-1,8 [], и керосиновых фракций подвергнутого гидрогенизации испанского сланцевого масла ['].

В настоящее время в промышленности США доля алкилбензолсульфонатов, производимых из парафиновых углеводородов, невелика. Однако, при создании промышленности моющих веществ в Советском Союзе алкилбензолсульфонатам, получаемым на базе парафиновых углеводородов нефтей, уделяется большое внимание.

Основными процессами, из которых состоит синтез алкилбензолсульфонатов из парафиновых углеводородов, являются: 1) хлорирование исходных углеводородов, 2) алкилирование бензола хлористыми алкилами, 3) сульфирование полученных алкилбензолов. Для керосиновых фракций нефтей применяется предварительная деароматизация.
\end{abstract}

Цель настоящей работы заключалась в исследовании возможности переработки парафиновых углеводородов, выделяющихся из сульфомассы, полученной при сульфировании алкилароматических углеводородов из олефинов сланцевой смолы. При этом для получения алкилароматических углеводородов использовались два несколько отличных друг от друга режима алкилирования. При первом режиме, называемом условно режимом «алкилирования», фракция сланцевой смолы $\left(160-310^{\circ}\right)$, очищенная $\mathrm{ZnCl}_{2}$, прибавлялась постепенно к тройному 
количеству бензола, смешанного с $10 \% \mathrm{AlCl}_{3}$, считая на фракцию. Продолжительность процесса составляла 5 часов, температура - от 30 до $60^{\circ}$. При втором режиме, называемом в дальнейшем «полимеризацией», очищенная $\mathrm{ZnCl}_{2}$ фракция сланцевой смолы перерабатывалась без бензола в присутствии $9 \% \mathrm{AlCl}_{3}$ при $100^{\circ}$ в течение 5 часов. При таком режиме переработки большее значение приобретают реакции полимеризации олефиновых углеводородов.

Выходы продуктов при этих режимах различны: при алкилировании получается больше моющих веществ (40\% от исходной фракции) и меньше смазочных масел $(21 \%)$, при полимеризации - больше смазочных масел $(32 \%)$ и меньше моющих веществ $(24,8 \%)$. Количество выделенных непреврашенных углеводородов также различно: при алкилировании оно составляет около $20-25 \%$, при полимеризации $35 \%$, считая на исходную фракцию.

С ы р ьем для получения моющих веществ типа алкилбензолсульфонатов в наших опытах служили: 1) парафино-нафтеновые углеводороды, выделенные при переработке исходной фракции при режимах алкилирования и полимеризации; 2) парафино-нафтеновые углеводороды, выделенные обработкой смесью Каттвинкеля из фракции сырой смолы; 3) парафиновые углеводороды, выделенные смесью Каттвинкеля из полимеризата, полученного при переработке легких бензиновых фракций $\mathrm{AlCl}_{3}$. Свойства исходных углеводородов приведены в табл. 1.

Таблица 1

Свойства исходных фракций

\begin{tabular}{|c|c|c|c|c|c|}
\hline $\begin{array}{l}\frac{\pi}{2} \\
\frac{5}{3} \\
0 \\
\text { 일 }\end{array}$ & $\begin{array}{c}\text { Способ получения } \\
\text { фракции }\end{array}$ & $\begin{array}{l}\text { Удельный } \\
\text { вес } d_{4}^{20}\end{array}$ & $\begin{array}{l}\text { Коэффи- } \\
\text { циент } \\
\text { преломле- } \\
\text { мия } n_{D}^{20}\end{array}$ & $\begin{array}{l}\text { Бромное } \\
\text { число }\end{array}$ & $\begin{array}{c}\text { Вязкость } \\
\text { при } 20^{\circ}, \\
\text { сст }\end{array}$ \\
\hline 1 & Сульфирование калкн- & 0,8081 & 1,4440 & 6,2 & 2,38 \\
\hline $\begin{array}{l}2 \\
3\end{array}$ & To же & 0,8098 & 1,4490 & 6,5 & 3,16 \\
\hline & $\begin{array}{l}\text { Сульфирование «nо- } \\
\text { лимеризата» }\end{array}$ & 0,8061 & - & 1,7 & 3,07 \\
\hline & $\begin{array}{l}\text { Каттвинкеля из } \\
\text { фракции } 170-300^{\circ} \\
\text { полимеризата }\end{array}$ & 0,8115 & 1,4470 & 0 & 3,89 \\
\hline $6,7,8$ & $\begin{array}{l}\text { То же сланцевой } \\
\text { смолы }\end{array}$ & 0,7949 & 1,4381 & 0 & 2,24 \\
\hline
\end{tabular}

\section{Методика опытов}

Хлорирование исходного сырья проводилось при температуре $50-65^{\circ}$ и освещении до содержания хлора $16-21 \%$. Қатализаторы не использовались. Время, необходимое для хлорирования, составляло 6-10 часов.

Алкилирование бензола хлорпарафинами производилось в присутствии $5-10$ вес. \% $\mathrm{AlCl}_{3}$. Последний прибавлялся к трехкратному по отношению $\mathrm{k}$ используемому сырью количеству бензола. Хлорпарафины добавлялись из капельной воронки постепенно, в течение $1,5-2$ часов, при $20-25^{\circ}$, затем перемешивание продолжалось 
4 часа при $50-60^{\circ}$. От реакционной смеси оттонялся бензол, алкилат отделялся от комплекса и разгонялся в вакууме на фракцию до $360^{\circ}$ и остаток.

В опытах 3, 5, 6 и 7 (табл. 2) су̀льфированию подвергали весь алкилат, в остальных опытах фракцию до $360^{\circ}$. Сульфирование производилось $10 \%$-ным олеумом, взятым в количестве $150 \%$ от фракции, при $4-5^{\circ}$ в течение 3 часов. Выделенные сульфокислоты подвергались нейтрализации 20\%-ным раствором $\mathrm{NaOH}$.

В полученных моющих веществах определялось содержание влаги и активного вещества. Для водных растворов моющих веществ производилось определение поверхностного натяжения на приборе Ребиндера и пенообразующей способности [?]. Анализ смазочных масел производился в соответствии с требованиями ГОСТ.

\section{Результаты опытов}

Выход алкилата при переработке хлорированных парафиновых углеводородов составляет от 80 до $100 \%$ на исходные хлорпарафины, количество комплекса с $\mathrm{AlCl}_{3} 20-30 \%$, а при использовании $5 \%$ оно уменьшается до 8-13\%. Количество регенерированного бензола составляет $80-90 \%$ от исходного. Потери в опытах алкилирования очень велики и достигают $20-30 \%$ от взятых на реакцию хлорпарафинов и бензола. Количество непревращенных парафинов изменяется в отдельных опытах очень значительно и, по-видимому, зависит от полноты отделения их от полученных сульфокислот. Выход активного вещества моющих в пересчете на прореагировавшие парафины достигает $80-85 \%$,

\section{таблица $2 \quad 20-25 \%$. \\ Таблиқа 2 та 20}

выход смазочных масел

Поверхностное натяжение водных растворов моющих веществ (эрг/ $\left.\mathrm{cm}^{2}\right)$

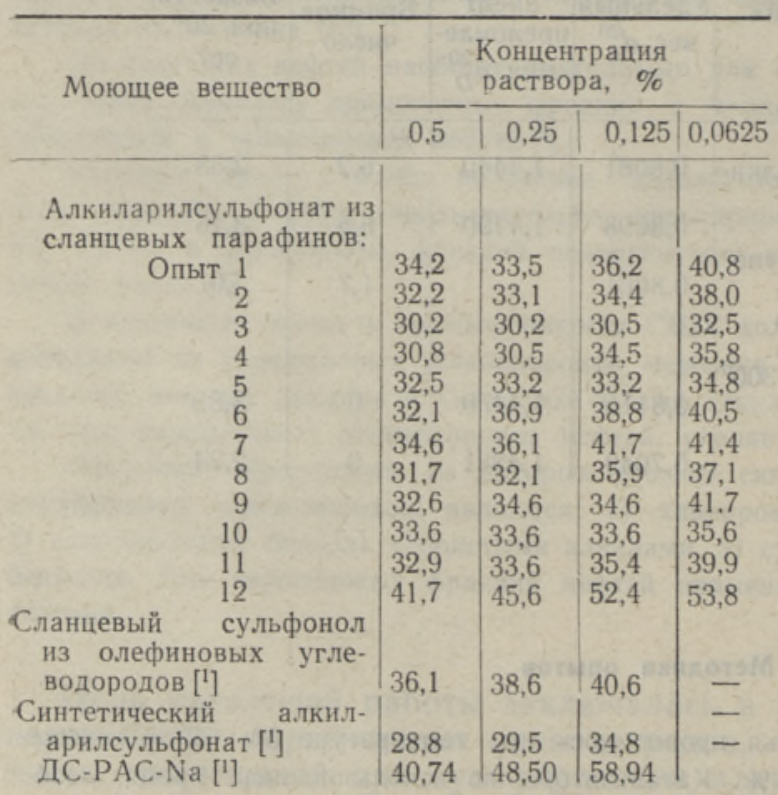
д данные о поверхностном натяжении, пенообразующей способности и моющих свойствах полученных моющих веществ в сравнении с аналогичными свойствами синтетического алкиларилсульфоната, ДС-РАС$\mathrm{Na}$ и сланцевого сульфонола (из олефинов сланцевой смолы).

Из данных табл. 2 и 3 видно, что все образцы моющих веществ, полученных из парафиновых углеводородов сланцевой смолы, независимо от условий проведения процесса алкилирования, по поверхностному натяжению и пенообразующей способности сходны между собой.

Лучшие из этих образцов имеют поверхностное натяжение, близкое к поверхностному натяжению синтетического алкиларилсульфоната, большинство значительно превосходит по поверхностному натяжению ДС-PAC-Na, а также сланцевый сульфонол, полученный из 
Таблица 3

Пенообразующая способность водных растворов моющих веществ (мм)

\begin{tabular}{|c|c|c|c|c|c|c|c|c|c|}
\hline \multirow{4}{*}{ Моюшее вещество } & \multicolumn{9}{|c|}{ Концентрация. раствора, \% } \\
\hline & \multicolumn{3}{|c|}{0,5} & \multicolumn{3}{|c|}{0,25} & \multicolumn{3}{|c|}{0,125} \\
\hline & \multicolumn{9}{|c|}{ Время измерения высоты столба пены, сек } \\
\hline & 0 & 30 & 360 & 0 & 30 & 360 & 0 & 30 & 360 \\
\hline $\begin{array}{l}\text { Алкиларилсульфонат из } \\
\text { сланцевых парафинов: }\end{array}$ & & & & & & & & & \\
\hline $\begin{array}{r}\text { Onыт } 1 \\
2 \\
3 \\
\quad \\
4 \\
5 \\
6 \\
7 \\
8 \\
9 \\
10 \\
11 \\
12\end{array}$ & $\begin{array}{l}311 \\
260 \\
290 \\
240 \\
283 \\
270 \\
255 \\
310 \\
309 \\
335 \\
363 \\
240\end{array}$ & $\begin{array}{l}185 \\
194 \\
194 \\
145 \\
181 \\
220 \\
180 \\
200 \\
205 \\
200 \\
290 \\
140\end{array}$ & $\begin{array}{l}162 \\
175 \\
175 \\
127 \\
171 \\
184 \\
150 \\
184 \\
187 \\
201 \\
274 \\
110\end{array}$ & $\begin{array}{l}270 \\
260 \\
245 \\
260 \\
258 \\
190 \\
215 \\
278 \\
285 \\
317 \\
360 \\
270\end{array}$ & $\begin{array}{l}160 \\
164 \\
152 \\
170 \\
140 \\
105 \\
160 \\
186 \\
168 \\
199 \\
282 \\
170\end{array}$ & $\begin{array}{r}146 \\
156 \\
140 \\
160 \\
130 \\
75 \\
140 \\
174 \\
159 \\
183 \\
262 \\
40\end{array}$ & $\begin{array}{l}244 \\
270 \\
240 \\
240 \\
263 \\
220 \\
225 \\
263 \\
282 \\
317 \\
361 \\
220\end{array}$ & $\begin{array}{l}136 \\
168 \\
150 \\
150 \\
168 \\
170 \\
150 \\
166 \\
163 \\
197 \\
289 \\
120\end{array}$ & $\begin{array}{r}126 \\
155 \\
137 \\
140 \\
152 \\
148 \\
128 \\
152 \\
152 \\
183 \\
274 \\
85\end{array}$ \\
\hline Сланцевый сульфонол & 345 & 280 & 255 & 335 & 272. & 255 & 320 & 260 & 235 \\
\hline $\begin{array}{l}\text { Синтетический } \\
\text { арилсульфонат ['] } \\
\text { ДС-PAC-Na['] }\end{array}$ & $\begin{array}{l}260 \\
275\end{array}$ & $\begin{array}{l}235 \\
235\end{array}$ & $\begin{array}{l}210 \\
225\end{array}$ & $\begin{array}{l}260 \\
235\end{array}$ & $\begin{array}{l}235 \\
196\end{array}$ & $\begin{array}{l}210 \\
185\end{array}$ & $\begin{array}{l}250 \\
140\end{array}$ & $\begin{array}{r}215 \\
95\end{array}$ & $\begin{array}{r}200 \\
90\end{array}$ \\
\hline
\end{tabular}

олефиновых углеводородов сланцевой смолы. Наиболее низкие показатели получены для образцов, сырьем для которых служили парафины, синтезированные из легких фракций (опыты 6, 7 и 12). Эти же образцы моющих продуктов показали и самое плохое пенообразование.

По пенообразующей способности и пеноустойчивости большинство полученных моющих веществ, кроме отдельных образцов (например, опыт 11), значительно уступают синтетическому алкиларилсульфонату и сланцевому сульфонолу. Несколько лучшую пенообразующую способность имеют моющие вещества, приготовленные из парафино-нафтеновой фракции сланцевой смолы, выделенные из нее обработкой серной кислотой и смесью Каттвинкеля (опыты 8, 9 и 10).

Для определения моющей способности алкилбензолсульфонатов, полученных из парафиновых углеводородов сланцевой смолы, была составлена суммарная проба из активного вещества нескольких образцов моющих (опыты 1, 2, 4, 11). Указанная проба была отправлена во Всесоюзный научно-исследовательский институт жиров. Испытание моющей способности проводилось в жесткой воде ( $15^{\circ}$ нем.)

Таблица 4

Моющая способность алкиларилсульфонатов из сланщевой смолы

\begin{tabular}{|c|c|c|c|c|}
\hline \multirow{2}{*}{ Моющее вещество } & \multicolumn{4}{|c|}{ Концентрация раствора, \% } \\
\hline & 0,5 & 0,375 & 0,25 & 0,125 \\
\hline Алкиларилсульфонат из & & & & \\
\hline $\begin{array}{l}\text { парафиновых углево- } \\
\text { дородов }\end{array}$ & 77 & 110 & 135 & 65 \\
\hline $\begin{array}{l}\text { Алкиларилсульфонат из } \\
\text { олефиновых углево- } \\
\text { дородов }\end{array}$ & & & & \\
\hline $\begin{array}{l}\text { Образец № } 1 \\
\text { Образец № } 2\end{array}$ & $\begin{array}{l}40 \\
54\end{array}$ & $\begin{array}{l}100 \\
108\end{array}$ & $\begin{array}{l}115 \\
123\end{array}$ & $\begin{array}{l}33 \\
42\end{array}$ \\
\hline
\end{tabular}

Примечание. За эталон принят алкилсульфат нз жирных спиртов кокосового масла. 
при температуре $50^{\circ}$. За эталон был принят алкилсульфат, полученный на основе жирных спиртов кокосового масла.

Приведенные в табл. 4 данные показывают, что исследованный образец моющего вещества, приготовленный из парафиновых углеводородов сланцевой смолы, по моющей способности несколько превосходит сланцевый сульфонол, приготовленный из олефиновых углеводородов сланцевой смолы, и так же, как и последний, обладает хорошим моющим эффектом при концентрации поверхностно-активного вещества от 0,25 до $0,37 \%$. При снижении концентрации до $0,125 \%$ моющая способность испытываемого образца алкилбензолсульфоната снижается. Такая закономерность наблюдается для всех образцов алкиларилсульфонатов.

Таким образом, парафиновые углеводороды, выделяющиеся при переработке олефинов сланцевой смолы в моющие вещества, необходимо подвергнуть дальнейшей переработке с целью получения из них моющих, которые при добавлении их к основному продукту не ухудшат, а, возможно, даже улучшат его качество.

Кроме моющих веществ, при переработке парафиновых углеводородов получаются и смазочные масла. Свойства некоторых из них приведены в табл. 5 .

Таблица 5

Свойства смазочных масел, полученных из парафиновых углеводородов сланцевой смолы

\begin{tabular}{|c|c|c|c|c|c|}
\hline \multirow{2}{*}{ Показатели } & \multicolumn{5}{|c|}{ № опыта } \\
\hline & 1 & 2 & 3 & 9 & 10 \\
\hline $\mathrm{y}_{\text {дельный }}$ вес $d_{4}^{20}$ & 0,9536 & 0,9452 & 0,9301 & 0,9618 & 0,9732 \\
\hline $\begin{array}{l}\text { Коэффициент преломле } \\
\text { ния } n_{D}^{20}\end{array}$ & 1,5389 & 1,5300 & 1,5145 & 1,5331 & 1,5490 \\
\hline Вязкость, сст, при $50^{\circ}$ & $\begin{array}{r}49,33 \\
8,06\end{array}$ & $\begin{array}{c}40,29 \\
7,1\end{array}$ & $\begin{array}{l}36,7 \\
6,47\end{array}$ & $\begin{array}{l}94,2 \\
11,3\end{array}$ & $\begin{array}{r}32,9 \\
5,8\end{array}$ \\
\hline $\begin{array}{l}\text { Отношение вязкости } \\
\text { при } 50^{\circ} \text { к вязкости } \\
\text { при } 100^{\circ} \\
\text { Индекс вязкости } \\
\text { Коксуемость, \% } \\
\text { Моторные свойства, \% }\end{array}$ & $\begin{array}{c}6,12 \\
40 \\
0,16\end{array}$ & $\begin{array}{c}5,7 \\
40 \\
0,24\end{array}$ & $\begin{array}{c}5,7 \\
30 \\
0,07\end{array}$ & $\begin{array}{l}8,3 \\
0 \\
0,28\end{array}$ & $\begin{array}{l}5,7 \\
10 \\
0,16\end{array}$ \\
\hline $\begin{array}{l}\text { испаряемость } \\
\text { рабочая фракщия } \\
\text { лак }\end{array}$ & $\begin{array}{c}92,2 \\
0 \\
7,8\end{array}$ & $\begin{array}{c}93,0 \\
0 \\
7,0\end{array}$ & $\begin{array}{c}92,3 \\
0 \\
7,7\end{array}$ & $\begin{array}{r}89,4 \\
4,4 \\
6,2\end{array}$ & $\begin{array}{r}96,5 \\
0,0 \\
3,5\end{array}$ \\
\hline
\end{tabular}

Смазочные масла, получаемые в виде остатка вакуумной дистилляции алкилата, представляют собой светлые продукты со слабой коксуемостью и низкими индексами вязкости. Такие низкие индексы вязкости характерны для смазочных масел, получаемых в условнях большого избытка ароматических компонентов.

На примере опытов 3 и 5 (табл. 2 и 3) показано, что вакуумную дистилляцию алкилата с выделением смазочных масел можно и не производить, так как при сульфировании суммарного алкилата получаются моющие вещества, обладающие такими же поверхностно-активными свойствами, как и продукты сульфирования фракций, выкипающих до $360^{\circ}$ (опыты $2,3,4,5$ в табл. 2 и 3 ).

Следовательно, вовлечение в переработку парафиновых углеводорсдов легких фракций сланцевой смолы дает дополнительное количество моющих средств и смазочных масел. Суммарный материальный 
баланс переработки очищенной хлористым цинком фракции сланцевой смолы, выкипающей в пределах $160-300^{\circ}$, при использовании режимов алкилирования и полимеризации приведен в табл. 6.

\section{Таблица 6}

Выходы продуктов при полной переработке очищенной фракции сланцевой смолы, выкипающей в пределах $160-300^{\circ}$

\begin{tabular}{|c|c|c|}
\hline $\begin{array}{c}\text { Получаемые продукты, вес. \% } \\
\text { от исходной фракции }\end{array}$ & $\begin{array}{l}\text { Алкилиро- } \\
\text { вание }\end{array}$ & $\begin{array}{l}\text { Полимери- } \\
\text { зация }\end{array}$ \\
\hline $\begin{array}{l}\text { Активное вещество моющих, полученное } \\
\text { при переработке исходной фракции } \\
\text { Активное вещество моющих, полученное } \\
\text { при переработке парафинов } \\
\text { В сего активного вещества моющих } \\
\text { Смазочное масло при переработке исход- } \\
\text { ной фракции } \\
\text { Смазочное масло из парафинов } \\
\text { Всего смазочных масел } \\
\text { Общ и й выход продуктов }\end{array}$ & $\begin{array}{r}20,1 \\
60,1 \\
\\
21,0 \\
6,3 \\
27,3 \\
87,4\end{array}$ & $\begin{array}{r}28,1 \\
52,9 \\
32,0 \\
8,3 \\
40,3 \\
93,2\end{array}$ \\
\hline
\end{tabular}

На основании данных приведенного баланса можно сказать, что прй полной переработке очищенных $\mathrm{ZnCl}_{2}$ легких фракций смолы можно

Таблица 7

Свойства поверхностно-активных веществ из исходной фракции и парафино-нафтеновых углеводородов

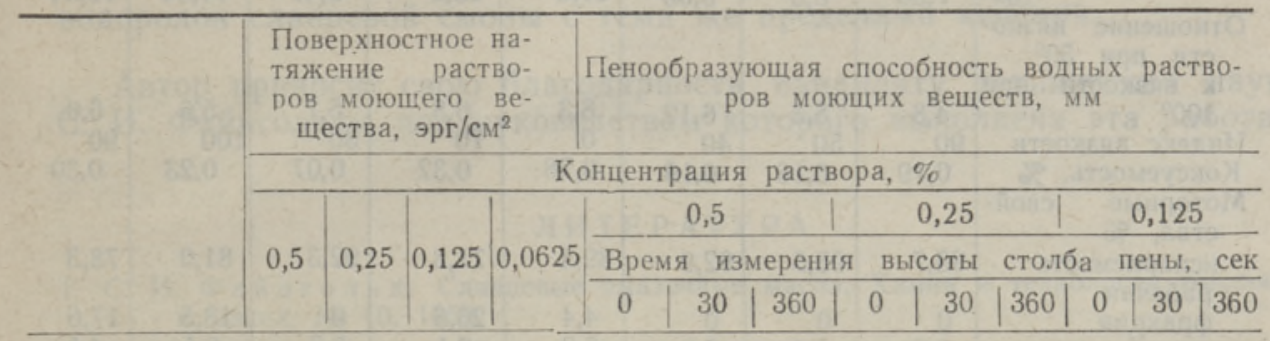

Алкилиров ани е

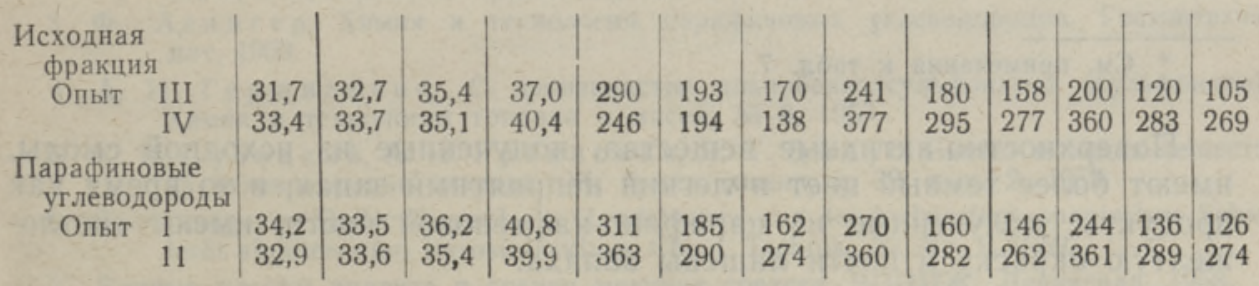

Полиме ри за и я

\begin{tabular}{l|l|l|l|l|l|l|l|l|l|l|l|l|l|}
$\begin{array}{l}\text { Исходная } \\
\text { фракция } \\
\text { Опыт K-16 }\end{array}$ & 32,0 & 35,3 & 41,1 & 47,0 & 316 & 204 & 180 & 245 & 150 & 130 & 220 & 150 & 125 \\
$\begin{array}{c}\text { Парафиновые } \\
\text { углеводороды } \\
\text { Опыт 4 }\end{array}$ & 30,8 & 30,5 & 34,5 & 35,8 & 240 & 145 & 127 & 260 & 170 & 160 & 240 & 150 & 140
\end{tabular}

П р и меч ан ия. 1. Данные о парафиновых углеводородах и выходе продуктов при алкилированни (опыты III и IV) взяты из специальных опытов.

2. Данные о парафиновых углеводородах и выходе продуктов при полимеризацин (опыт K-16) взяты из опыта, проведенного канд. техн. наук М. Корвом. 
получить около $90 \%$ продуктов, причем около $30 \%$ из них дает вовлечение в переработку парафиновых углеводородов.

Качество продуктов, получаемых при использовании различных режимов переработки смолы, различно. В табл. 7 приведены свойства поверхностно-активных веществ, полученных при переработке исходной фракции и ее парафино-нафтеновой части, а в табл. 8 - свойства получаемых смазочных масел.

Таблица 8

Свойства смазочных масел из исходной фракции и парафиновых углеводородов*

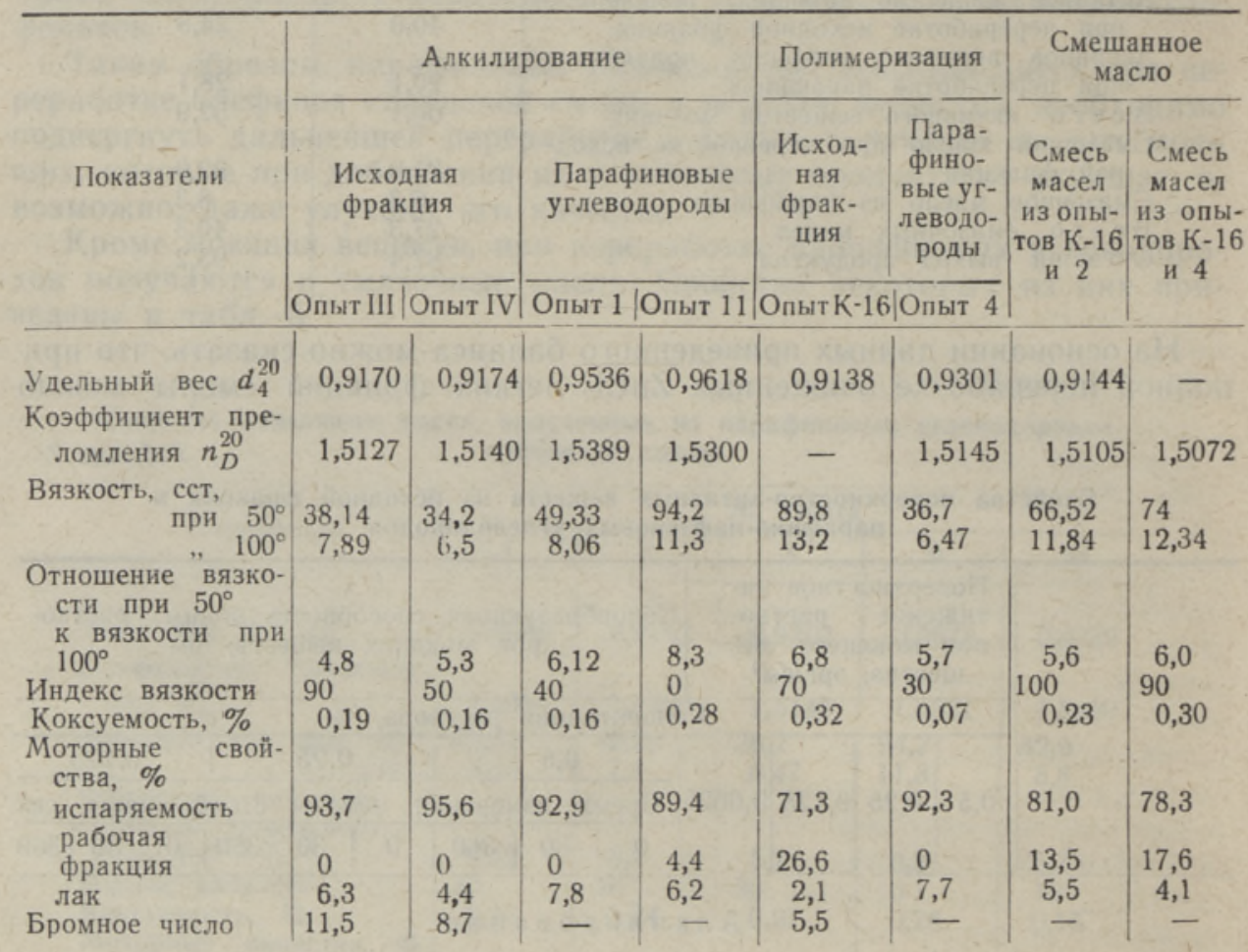

* См. примечания к табл. 7 .

Поверхностно-активные вещества, полученные из исходной смолы, имеют более темный цвет и легкий неприятный запах, в то время как продукты, полученные из парафино-нафтеновой части, имеют светложелтую окраску и почти лишены запаха.

Поверхностное натяжение и пенообразующая способность водных растворов моющих веществ, полученных из исходной фракции и парафино-нафтеновой ее части, почти одинаковы. Несколько худшим поверхностным натяжением обладает темный продукт, полученный при полимеризации исходной легкой фракции. Необходимо отметить, что при извлечении из темных сульфопродуктов несульфируемых соединений (например, петролейным эфиром) их цвет и запах значительно улучшаются. Поэтому вопрос о более полном отделении несульфируемых углеводородов от получаемых алкиларилсульфонатов для производства на их основе дополнительного количества продуктов тесно связан с вопросом улучшения качества основных продуктов. 
Рассматривая свойства смазочных масел, необходимо отметить хорошие вязкостно-температурные свойства масла, полученного при полимеризащии исходной легкой фракции (опыт К-16). Смешение его с маслом, полученным при переработке парафиновых углеводородов, в отношении 4:1 (табл. 6), дает смешанные масла, обладающие высоким индексом вязкости и хорошими моторными свойствами. Поэтому полимеризацию легких фракций смолы с последующей переработкой парафиновых углеводородов можно считать удачным методом одновременного получения смазочных масел и моющих вешеств.

\section{Выводы}

1. Парафиновые углеводороды, выделяемые при переработке олефиновых и ароматических углеводородов легких фракций сланцевой смолы, целесообразно использовать для получения из них моющих веществ типа алкиларилсульфонатов. Это дает дополнительно около $30 \%$ моющих вешеств и смазочных масел.

2. Метод переработки состоит в хлорировании парафиновых углеводородов, алкилировании бензола хлорпарафинами и последующем сульфировании алкилата или выделенной из него фракции, выкипающей до $360^{\circ}$. В последнем случае остаток вакуумной дистилляции используется в качестве смазочного масла.

3. Моющие свойства получаемых продуктов несколько лучше, чем моющие свойства алкиларилсульфонатов из олефиновых углеводородов сланцевой смолы с теми же пределами кипения.

Автор приносит свою благодарность кандидату технических наук С. И. Файнгольду, под руководством которого выполнена эта работа.

\section{ЛИТЕ РАТ У РА}

1. С. И. Файнгольд, Сланцевые смазочные масла, Химия и технология топлива и масел, № 10, 1959.

2. А. И. Гершенович, Синтетические анионные моющие вещества, Химическая наука и промышленность, т. I, № $3,1956$.

3. Ф. Азингер, Химия и технология парафиновых углеводородов, Гостоптехиздат, 1959.

4. А. И. Гершинович, О производстве алкилбензолсульфонатов (сульфонола), Химия и технология топлива и масел, № 8, 1957.

5. К. В. П уз и ц ки й, А. И. Р а б ин ови ч, Я. Т. Э йд у с, Синтез моющих веществ из углеводородов синтина, Ж. прикл. химин, т. 32 , вып. $2,1959$.

6. Gewinnung von Dodecylbenzol als Handelsware aus der hydriertem spanischen Schieferöl abgetrennten Kerosinfraktion. Chem. Technik, 50, Nr. 1, 1959.

7. Единые методы анализа и оценки моющих средств, ВНИИЖ, Ленинград, 1958.

Ннститут химии

Академии наук Эстонской ССР
Поступила в редакцию

19. II 1960 


\section{ALKOOLARUOLSULFONAATIDE TUUPI PESEMISVAHENDITE SAAMINE POLLEVKIVIOLI PARAFIINSETEST SUSIVESINIKEST}

\section{G. Stepanova,}

\section{tehnikakandidaat}

Resümee

Artiklis käsitletakse alküülarüülsulfonaatide tüüpi pesemisvahendite sünteesimise probleemi. Lähteaineks kasutatakse pōlevkiviõli kergete fraktsioonide töötlemisel kõrvalproduktidena eraldatud parafiinseid süsivesinikke. Meetod koosneb parafiinsete süsivesinike kloreerimisest kuni $20 \%$ kloori sisalduseni, bensooli alküleerimisest kloorparafiinidega ja sellele järgnevast alkülaadi sulfureerimisest ning sulfohapete neutraliseerimisest. Sünteesitud alküülbensoolsulfonaadid on pesemisomadustelt mōningal määral paremad põlevkiviōli olefiinsete süsivesinike vastavatest derivaatidest. Parafiinse ja nafteense osa eraldamine ja ümbertöötamine annab lähteōlile arvestatuna täiendavalt veel $30 \%$ pesemisvahendeid ja määrdeōlisid.

Eesti NSV Teaduste Akadeemia Keemia Instituut

\section{Saabus toimetusse}

19. II 1960

\section{OBTAINING OF DETERGENTS OF THE ALKYLARYLSULFONATE TYPE FROM PARAFFIN HYDROCARBONS OF SHALE OIL}

\section{G. Stepanova}

\section{Summary}

The article deals with the possibilitiy of utilizing paraffin hydrocarbons separated by the treatment of light fractions of shale oil for the obtaining of detergents of the alkylarylsulfonate type. The utilization of the paraffin-naphthene part of these fractions gives, in addition, about 30 per cent of detergents and lubricating oils on the initial fraction.

The method of processing consists in the chlorating of paraffin hydrocarbons until they contain about 20 per cent of chlorine, of alkylating the benzol with chloroparaffins and a subsequent sulfonating of the alkylate. The washing properties of the alkylbenzolsulfonates obtained in this way are somewhat more effective than those processed from olefinic hydrocarbons of shale oil.

Academy of Sciences of the Estonian S.S.R., Institute of Chemistry

Received Febr. 19th, 1960 